\section{Risk of systemic lupus erythematosus in patients with idiopathic thrombocytopaenic purpura}

We read the published article by Zhu $e t$ al ${ }^{1}$ with great interest. In this population-based retrospective cohort study, the authors demonstrated that the patients with idiopathic thrombocytopaenic purpura (ITP) had a 26 times higher risk of new-onset systemic lupus erythematosus (SLE) compared with the control population. However, some concerns do exist and should be addressed.

First, thrombocytopaenia is known as a common clinical manifestation of SLE and can be the initial presentation in 5\% of patients with SLE. ${ }^{23}$ The diagnosis of ITP is based principally on the exclusion of any known causes of thrombocytopaenia by history, clinical manifestations, physical examination, laboratory tests, bone marrow examination and so on. ${ }^{4}$ In the study, the search of patients with ITP was according to International Classification of Diseases, Ninth Revision, Clinical Modification code 287.3. In the setting of nationwide population, obviously, most patients with thrombocytopaenia initially see haematologists, rather than rheumatologists. Under the circumstances, some early stage of SLE patients with thrombocytopaenia as the only initial manifestation may be wrongly diagnosed as ITP and were included in ITP group in the study. Therefore, serious selection bias exists, which is, at least in part, attributable to the incredibly high HR. The authors should have checked the diagnosis of ITP before these patients were included in the ITP group. A potential solution is to exclusively include the patients with negative autoantibodies at the time of ITP diagnosis. Second, only $0.19 \%$ of patients in the non-ITP group developed SLE during follow-up. In the context of extremely low incidence rates, a cohort design is deeply challenging and problematic and usually lead to poor robustness of estimates, embodied in the particularly wide 95\% CI in the study (eg, 95\% CI 13.7 to 46.0). Meanwhile, although the authors had controlled a range of baseline characteristics, several considerable risk factors strongly related to developing SLE still failed to be adjusted, for example, family history of SLE (or rheumatic diseases) in first-degree relatives and smoking. ${ }^{5}$ The presence of residual factors was acceptable in some situation, but the confounding bias caused by confounding factors could be amplified in the presence of extremely low incidence rates and largely weakened the reliability of findings. In addition, we consider the time to the SLE for the two groups should be provided in the study.

Wenhui Xie $\odot$, Zhuoli Zhang $\odot$

Correspondence to Professor Zhuoli Zhang, Department of Rheumatology and Clinical Immunology, Peking University First Hospital, Beijing, China; zhuoli.zhang@126.com

Contributors WX wrote the paper. ZZ reviewed and edited the manuscript.

Funding The authors have not declared a specific grant for this research from any funding agency in the public, commercial or not-for-profit sectors.

Competing interests None declared.

Patient and public involvement Patients and/or the public were not involved in the design, or conduct, or reporting, or dissemination plans of this research.

Patient consent for publication Not required.

Provenance and peer review Not commissioned; internally peer reviewed.

(C) Author(s) (or their employer(s)) 2020. No commercial re-use. See rights and permissions. Published by BMJ.

\section{Check for updates}

To cite Xie W, Zhang Z. Ann Rheum Dis Epub ahead of print: [please include Day Month Year]. doi:10.1136/annrheumdis-2020-217659

Received 17 April 2020

Accepted 18 April 2020

Ann Rheum Dis 2020;0:1. doi:10.1136/annrheumdis-2020-217659

\section{ORCID iDs}

Wenhui Xie http://orcid.org/0000-0002-3881-0266

Zhuoli Zhang http://orcid.org/0000-0001-7219-9141

\section{REFERENCES}

1 Zhu F-X, Huang J-Y, Ye Z, et al. Risk of systemic lupus erythematosus in patients with idiopathic thrombocytopenic purpura: a population-based cohort study. Ann Rheum Dis 2020:annrheumdis-2020-217013.

2 Fayyaz A, Igoe A, Kurien BT, et al. Haematological manifestations of lupus. Lupus Sci Med 2015;2:e000078.

3 Hazzan R, Mukamel M, Yacobovich J, et al. Risk factors for future development of systemic lupus erythematosus in children with idiopathic thrombocytopenic purpura. Pediatr Blood Cancer 2006;47:657-9.

4 Provan D, Arnold DM, Bussel JB, et al. Updated international consensus report on the investigation and management of primary immune thrombocytopenia. Blood $A d v$ 2019;3:3780-817

5 Chua MHY, IAT N, Cheung MWL, et al. Association Between Cigarette Smoking and Systemic Lupus Erythematosus - an Updated Multivariate Bayesian Metaanalysis [published online ahead of print, 2019 Dec 1]. J Rheumatol 2019. 